\title{
La práctica del método psicoprofiláctico para el parto sin dolor en Medellín (Colombia) ${ }^{(*)}$
}

\section{Doctores Gustavo Isaza Mejía (*;), Jorge Muñoz Moreno y Leonidas Rodríguez $\mathbf{R}$.}

En septiembre de 1956 instalamos en Medellín el Método sicoprofiláctico para el parto sin dolor, de acuerdo con el sistema que aprendimos al lado del profesor Fernando Lamaze en la maternidad de los Metalúrgicos de París.

Desde el mismo momento hemos tenido que luchar arduamente contra todos los obstáculos que se nos han presentado; nuestro ambiente es desconfiado y acepta con dificultad las innovaciones. Las madres antioqueñas positivistas y poco dadas a las inquietudes intelectuales, poseedoras de una tradición milenaria, rechazan a priori todo aquello que indique cambio en sus costumbres.

A lo anterior y a muchos otros motivos que se nos escapan, se riebe probablemente el hecho de que a pesar de llevar ya dos años y medio en la práctica del método sicoprofiláctico, solamente hemos logrado preparar 260 señoras, en pequeños grupos de 12 a 15 y sin discriminaciones de edad del embarazo, capacidad intelectual, posición económica, etc., factores éstos tan importantes en el éxito; tampoco poseemos un centro apropiado para la atención del parto, ya que la gran mayoría de las señoras pertenecen o son clientas de los diferentes obstetras de la ciudad, quienes emplean otros sistemas.

Así tenemos, pues, dos grupos: el primero consta de 172 señoras preparadas sicológicamente y atendidas durante el parto de

(*) Trabajo presentado al Primer Simposio Colombiano sobre métcdos sicofísicos de analgesia obstétrica celebrado en Bogotá en febrero de 1959.

(**) Dirección: Medellín - Colombia. Calle 53, número 42-85. 
acuerdo con el método y 88 señoras preparadas también pero atendidas con otros sistemas.

Para valorar los resultados nos valemos de una encuesta igual a la que se usa en la Clínica Palermo y que es contestada por las señoras al día siguiente de su parto; otras señoras, además de contestar la encuesta, envían una descripción más detallada y de las cuales daremos algunas de las frases más llamativas.

\section{Programa}

Como explicamos al principio seguimos el mismo programa dé la maternidad de los Metalúrgicos de París y así tenemos las clases en número de 10 solamente.

\section{fa Clase}

Recuento histórico del Método.

Lectura de informes hecho por las señoras que ya hicieron su parto de acuerdo con las enseñanzas.

Opinión de la Iglesia Católica al Método.

¿a. Clase

a) Anatomía del sistema nervioso cerebro-espinal y del sistema nervioso vegetativo de una manera muy superficial.

b) Anatomía de la pelvis ósea y de los órganos genitales exterzos e internos.

c) Fecundación, nidación y evolución del embarazo.

\section{$3^{a}$ Clase}

Concepción de Bichat frente al sistema nervioso. Modificación de I. P. Pavlov. Reflejos: Absolutos. Condicionados, descondicionados y recondicionados. Potencial Nervioso.

\section{4a Clase}

Anatomía y fisiología elemental del aparato respiratorio. Respiración. Enseñanza del primer ejercicio: "Soplar la vela". Segundo ejercicio: Reconocimiento de las contracciones uterinas.

\section{5 a Clase}

Mecanismo del parto. Período de dilatación y comportamiento correspondiente durante la contracción uterina. Tercer ejercicio respiratorio: Respiración uniforme.

\section{Clase}

Período expulsivo y comportamiento correspondienta: Quinto ejercicio. 


\section{rạ Clase}

Educación neuromuscular y enseñanza del Séptimo ejercicio: La relajación muscular física y mental.

\section{8a Clase}

Algunas enseñanzas de Puericultura a cargo del pediatra.

\section{9a Clase}

Funcionamiento del cerebro en el parto sin dolor: Repaso de sicología reflexológica. Reacción incondicional, condicionada, razonamiento lógico. Formación de frenos o barreras alrededor de los centros corticales y sub-corticales.

\section{Clase}

Conferencia sobre temas sicológicos: el valor de la palabra, algunas concepciones sobre el dolor, ventajas del método, y proyección de la película La Maternidad sin Dolor, filmada en París y dirigida por el servicio del profesor F. Lamaze.

Las clases se dictan cada 8 dias, su duración máxima es de una hora; los primeros minutos se dedican al repaso de la clase anterior. La enseñanza es esencialmente objetiva, para lo cual poseemos material adecuado: maniquí obstétrico, pelvis ósea, cuadros, proyecciones y película.

La clase $5^{a}$ (período de dilatación), doctor Leonidas Rodríguez R. y la 6a (período expulsivo), por el doctor Jorge Muñoz Moreno (obstetra).

La 8a Nociones de Puericultura están a cargo del doctor Rogelio Londoño (Pediatra). Las demás clases son dictadas por el äoctor Gustavo Isaza Mejía (Ginecólogo).

\section{Atención del parto}

Para la atención del parto dejamos la elección de la clínica al gusto de la señora; procurando que desde un principio se encuentre con ella, la enfermera preparada en el método para evitar contratiempos y errores del personal existente en nuestras clíricas, personal por lo demás inexperto y sin ningún conocimiento de los métodos sicológicos.

El obstetra vigila desde un principio la evolución del trabajo, procurando estar al frente y en forma constante todo el tiempo que le sea posible, pero muy especialmente desde 5 centímetros del período de dilatación hasta finalizar el parto. 
Drogas.-Empleamos el oxígeno a voluntad de la paciente y algunas inyecciones intravenosas de suero glucosado hipertónico cuando se observan signos de fatiga general o uterina. Los ocitócicos se emplean muy rara vez y hemos observado que las madres bien preparadas y conscientes, los toleran sin inconvenientes, en cambio las que no astán muy bien preparadas, corren el peligro de descontrolarse completamente.

\section{Control de los resultados}

Hemos dividido los casos que presentamos en 2 épocas: la primera desde la iniciación del método hasta diciembre de 1957, serie ésta que fue presentada a la III Convención de Ginecología y Obstetricia de la ciudad de Ibagué; con 90 casos discrimizados así:

50 partos sin ningún dolor.

25 partos con dolores soportables que no necesitaron anestesia.

15 partos con dolor en el período final de la dilatación y en el expulsivo principalmente, que hizo necesaria la aplicación de anestesia.

Como lo anotamos en aquella oportunidad, los fracasos fueIon por lo demás relativos o parciales y en una proporción mayor del $15 \%$. Decíamos que relativos porque las madres si bien no se libraron de la anestesia, sí obtuvieron como ellas mismas lo atestiguaron grandes beneficios durante su embarazo: mejoría o curación total de los trastornos simpáticos y sobre todo lo más interesante fue la verdadera transformación de su siquismo; las madres se vuelven más tranquilas, serenas y conscientes, pierden por sompleto el temor al embarazo y al parto.

La segunda época comprende todo el año de 1958: durante el cual preparamos y fueron atendidas por el obstetra y la enfermesa conocedores del método, 52 señoras cuyos resultados adjuntamos.

Advertencia.-Consideramos las calificaciones así: cinco (5), cuando la señora hace su parto sin fatiga, sin dolor y a plena conciencia; cuatro (4), cuando aparecen algunos signos de fatiga o dolor ligero en el periodo final; tres (3), tendencia al descontrol pero reparable, dolor leve pero persistente, y fatiga, pero sin necesidad de anestesia; dos (2) fracaso total en el período de dilatación y anestesia al final.

De los 52 casos atendidos en estas condiciones no se ha presentado ninguno de calificación dos, en cambio si se ha presen- 
tado frecuentemente en los casos preparados pero atendidos por otros sistemas.

Nos hemos mantenido fieles al sistema sicológico y no usamos ios ejercicios gimnásticos del método de Read por varias razones:

a) Estos ejercicios complican el sistema haciendo as! más difícil su aceptación por el público.

b) Como lo comentamos al principio, entre nosotros es difícil que las madres hagan estas prácticas, en parte porque no son aficionadas y en segundo lugar porque es muy difícil borrarles de la mente la idea errónea que ellas tienen de que son peligrosos.

c) En cambio de ello, damos gran importancia a la educación neuromuscular "La Relajación Muscular", pues hemos creído que este sistema no solamente reemplaza a la gimnasia sino que la supera con creces; ya que conduce al dominio directo y personal de las sensaciones que provienen de los músculos esqueléticos, de los órganos de los sentidos y de la musculatura de los órganos internos, control respiratorio y cardiovascular en forma consciente y dirigida; claro que este control no es absoluto, como sucede en los individuos que practican las doctrinas yogas, pero sí es al menos parcial y adecuado a las contracciones uterinas.

Creemos que esto se deba al hecho de que muchas de las señoras cuyos partos a pesar de haber sido atendidos en forma un poco inadecuada al sistema, algunas han sido capaces, sin embargo, de sobreponerse y vencer esas dificultades para lograr un parto en perfectas condiciones, sin dolor, y otras con dolor soportable. A una de estas señoras le hicieron una aplicación de fórceps sin anestesia y ella nos confesó luego que no había sentido ningún alolor.

Otra de las ventajas que hemos observado en el método sicoprofiláctico es la mejoría total o casi total de los síntomas simpáticos del embarazo: náuseas, vómitos, calambres, dolores lumbares, cefaleas, desde las primeras clases; ésta es una de las razones por las cuales no nos oponemos a que las madres empiecen los cursos desde los primeros meses. Otro de los motivos se debe a la creencia que tenemos de la importancia de la relajación muscular y es bien sabido que esta discipíña es más efectiva mientras más prolongada sea su práctica.

Hemos observado también grandes modificaciones o mejor verdaderas transformaciones en el mecanismo del parto en sí mismo; tenemos dos casos de señoras que en sus partos anteriores fue siempre necesaria la intervención quirúrgica (cesárea), una 
de 3 partos, otra de 4 y con este método la dilatación y el período expulsivo fueron en forma normal, espontánea.

Resumen de algunos casos atendidos por el Método Sicoprofiláctico Calificación 5

1. C. D. de J.-Multípara. Duración 5 horas. Sin dolor ni fatiga.

2. C. P. de A.-Primípara. Duración de dilatación 12 horas. Distocia de la misma en 5 centímetros. Sin dolor ni fatiga.

3. M. B. de T.-Multípara. 4 horas. Sin dolor ni fatiga.

4. L. M. de U.-Multípara. 18 horas con distocia de dilatación. Sin dolor ni fatiga. Cesárea.

5. J. C. de V.-Primípara. 6 horas. Sin dolor ni fatiga.

6. H. R. de D.-Primípara. $5 \frac{1}{2}$ horas. Sin dolor ni fatiga.

7. M. de F. B.-Primípara. 4 horas. Sin dolor ni fatiga.

8. L. G. de P.-Multípara. 31/2 horas. Sin dolor ni fatiga.

9. N. B. de P.-Primípara. 10 horas. Sin dolor ni fatiga.

10. L. G. de T.-Multípara. 3 horas. Sin dolor ni fatiga.

11. L. C. de C.-Multípara. $4 \frac{1}{2} 2$ horas. Sin dolor ni fatiga.

12. L. T. de A.-Multípara. 6 horas. Sin dolor ni fatiga.

13. E. G. de A.-Multípara. 5 horas. Sin dolor ni fatiga.

14. L. P. de R.-Primipara. 5 horas. Sin dolor ni fatiga.

i5. R. M. de R.-Multípara. 4 horas. Sin dolor ni fatiga.

16. M. de M.-Primípara. 5 horas. Sin dolor ni fatiga.

17. L. A. de G.-Multípara. $2 \frac{1}{2}$ horas. Sin dolor ni fatiga.

"Cuando una ha tenido tantos partos es cuando mejor puede apreciar los beneficios del Método Sicoprofiláctico".

18. A. Nobel de R.-Multípara. $3 \frac{1}{2}$ horas. Sin dolor ni fatiga.

19. C. de G.-Primipara. $4 \frac{1}{2} 2$ horas. "Me convencí de que el do" lor es absurdo y que con el método desaparecen todos los temores".

20. L. de H.-Multípara. $2 \frac{1}{2} 2$ horas. "Puedo asegurar que el método en mi concepto es el beneficio más grande que las madre: podemos recibir, y quisiera que todas las madres de Colombia 10 conocieran para bien de ellas y de nuestros hijos".

21. L. A. de P.-Multípara. 3 horas. "Con el método se terminan los dolores y angustias de las madres que hasta la época actual rada sabíamos de lo que ocurre en nuestro interior, y que sólo estábamos sometidos a escuchar, indefensas, las supersticiones y errores en nuestro ambiente”.

22. M. de F. B.-(Ver número 7). "No solo es recomendable sino que todas deben beneficiarse y seguir el Método Sicoprofilác- 
tico, ya que en mi caso solo me bastó estudiar sin asistir a las clases para que mi éxito fuera perfecto".

23. M. S. de S.-Multípara. 5 horas. Sin dolor ni fatiga.

24. M. L. de R.-Multípara. 4 horas. Sin dolor ni fatiga.

25. M. I. de A.-Multipara. 5 horas. Sin dolor ni fatiga.

26. L. de A.-Multípara. 3 horas. Sin dolor ni fatiga.

"Yo hab'a tenido dos hijos con anestesia y me creía incapaz de tener otro sin ella. Sinembargo me pareció ミencillísimo y estoy muy convencida de la bondad del método".

27. A. de L.-Multípara. $3 \frac{1}{2}$ horas. Sin dolor ni fatiga.

28. B. M. de P.-Multipara. 5 horas. Sin dolor ni fatiga.

29. A. de G.-Multípara. $3 \frac{1}{2} 2$ horas. Sin dolor ni fatiga.

30. B. Car. de G.-Multipara. 4 horas. Sin dolor ni fatiga.

\section{Calificación 4}

1. C. D. de J.-Multípara. Duración 5 horas. Sin dolor ni fatiga.

2. B. A. de Y.-Primpara. 10 horas. Ligero dolor, sin fatiga.

3. L. R. de P.-Multipara. 5 horas. Dolor lumbar en expulsivo.

4. L. B. de S-Primípara. 7 horas. Fatiga expulsivo, sin dolor.

5. L. M. de L.-Primípara. 5 horas. Intervención por estenosis mitral en 1954. Fatiga sin dolor.

6. L. C. de L.-Multipara. 3 horas. Fatiga expulsivo.

7. H. P. de R.-Mult para. 4 horas. Fatiga en expulsivo. Sin त.olor.

8. A. G. de G.-Primípara. $4 \frac{1}{2}$ horas. Dolor tolerable.

9. A. J. de S.-Muitípara. 7 horas. Dolor tolerable.

10. B. M. de J.-Multípara. 4 horas. Dolor tolerable. Sin fatiga.

11. L. C. de C.-Multípara. $4 \frac{1}{2}$ horas. Sin dolor ni fatiga.

12. A. Z. de L.-Multípara. $4 \frac{1}{2}$ horas. Cansancio expulsivo.

13. A. C. de M.-Multípara. 5 horas. Sin dolor pero fatiga.

14. M. G. de G.-Mult:para. 6 horas. Dolor lumbar.

15. M. T. M. de B.-Multípara. 5 horas. "Atribuyo dolores por jo ser atendida por médicos del método".

16. A. O. de U.-Multípara. 4 horas. Fatiga en región lumbat:

17. L. G. de T.-Multípara. 6 horas. Dolor tolerable con un feto grande de 4.550 gramos y 57 centímetros de largo.

18. J. C. de C.-Muitípara. 3 horas. Descontrol al principio por cápsulas de quinina que hicieron desarreglar el ritmo de las contracciones.

19. R. D. de M.-Multipara. 5 horas. Expulsivo con dolor tolerable. 


\section{Calificación 3}

1. O. E. de H.-Multípara. $3 \frac{1}{2} 2$ horas. Descontrol y dolor en el expulsivo.

2. L. de P.-Multípara. Según informe a la letra: "Fui atendida por un médico que no sabía el método y me desconcertó el que dijese que la relajación era lo único que servía, pues para él la respiración era nula".

3. G. L. de U.-Multípara. Atendida sin saguir al método. No obstante el dolor fue tolerable. Fórceps.

\section{Resumen}

Con Calificación $5=30$

Frimiparas $=8$

Duración 3 horas $=0$

Multiparas $=22$

Duración de 3 a 5 horas $=3$

$+=5$

$=19$

Duración de 5 a 10 horas $=4$

$=2$

Con Calificación $4=19$

Primíparas $=4$

Duración 3 horas $=0$

Multiparas $=15$

Duración de 3 a 5 horas $=2$

$=2$

Duración de 5 a 10 horas $=2$

$=8$

$=5$

Con Calificación $3=3$

Primíparas $=0$

Multíparas $=3$

Medellin, diciembre 16 de 1858 


\section{CLASES PRACTICAS \\ (EXTRACTO DEL FOLLETO ENTREGADO A LAS PACIENTES)}

\section{PRIMER EJERCICIO}

Es necesario que la madre se prepare para el período final del parto, momento en que entran en juego, las fuerzas musculares y respiratorias ayucladas por el cerebro, que estará/activo y alerta, en plena conciencia, esperando las contracciones del útero y las órdenes del partero. En este momento se requiere que la madre sepa llenar sus pulmones de una gran cantidad de aire (inspiración muy profunda), que a la vez que le permite bajar el diafragma para colocarse con el fondo uterino apoyándose en él y ayuda en esta forma a la progresión del niño a través del canal vaginal. El ejercicio que conduce a esta finalidad se llama "Soplar con la vela".

Soplar con la vela.-Como su nombre lo dice, este ejercicio se ejecuta soplando el aire de la espiración a través de los labios un poco cerrados como para silvar y orientando el aire hacia adelante imaginándose que se desea soplar la llama de una vela, sin apagarla, situada a unos 50 centímetros de distancia.

Al principio debe hacerse este ejercicio en forma práctica y real; colóquese una vela encendida sobre una mesa situada a 50 centímetros de distancia de la boca.

Sentada o de pies, con los hombros caídos y los brazos sueltos, empiece los ejercicios, así:

a) Inspiración (entrada del aire por la nariz).

b) Espiración (salida del aire por la nariz y la boca al mismo tiempo); sin dejar salir todo el aire.

c) Con la proporción del aire que quedó en los pulmones, el aire residual, trate de soplar la vela que tiene a 50 centímetros de distancia de la boca.

Resumen (3): Tres tiempos:

$1^{\circ}$ Inspiración.

$2^{\circ}$ Espiración.

$3^{\text {o }}$ Soplar con la vela.

Para empezar el entrenamiento se hará en forma fácil y suave; cada día uno de los tres tiempos muy cortos procurando repetirlos veinte veces en un minuto (veinte grupos de tres).

Repetirlo en la misma forma 3 veces durante 3 días; luego cada día rebajará un grupo de tal manera que al cabo de 4 días, la madre estará en condiciones de hacer solamente seis (6) grupos de a tres en un minuto, así:

$1^{\text {o }}$ día $=20$ Grupos de a 3 en un minuto.

$2^{\text {o }}$ día $=20$ Grupos de a 3 en un minuto.

$3^{\circ}$ día $=19$ Grupos de a 3 en un minuto.

$4^{\circ}$ día $=18$ Grupos de a 3 en un minuto.

$5^{0}$ día $=17$ Grupos de a 3 en un minuto.

$6^{\circ}$ día $=16$ Grupos de a 3 en un minuto. 


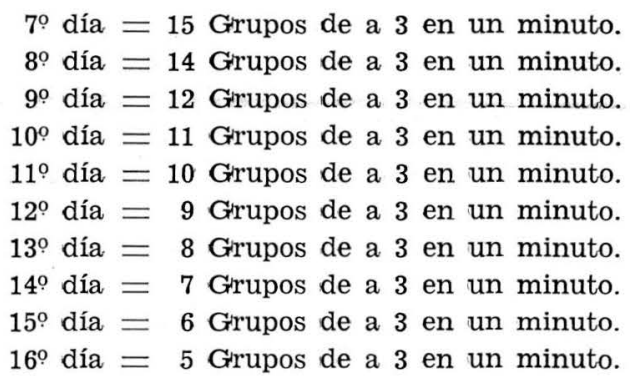

Téngase bien presente que este ejercicio no se necesita en ningún momento del parto; solamente tiene por objeto la preparación de la madre para la inspiración profunda del período expulsivo. Como fácilmente se puede observar al practicarlo, cada día se va haciendo la inspiración y la espiración de manera más profunda y prolongada.

\section{SEGUNDO EJERCICIO}

\section{Estudio de las contracciones del útero (matriz)}

Este segundo ejercicio no tiene hora determinada; se estudia cada vez que se presente la contracción del órgano que alberga el futuro hijo (el útero o matriz) .

Cada vez que sienta un endurecimiento del vientre, a partir del quinto mes generalmente, y con ocasión de un movimiento del niño, la madre colcará sus dos manos sobre el abdómen, por debajo del ombligo, para apreciarlo mejor. Así observará cómo el útero empieza a enđurecerse de afuera hacia el centro, durante unos veinte segundos y luego se pone nuevamente blando en sentido contrario.

Este fenómeno es' "La contracción uterina" y' dura aproximadamente cuarenta segundos y se presenta de vez en cuando; a veces se observan cuando la madre hace los ejercicios respiratorios; pues el niño recibe el oxígeno del aire, recibe más vida.

Es importante que la madre se dé muy buena cuenta de que estas contracciones no producen ningún dolor; y que éste es el mismo fenómeno que se presenta durante el parto; en, este momento en forma rítmica y con más intensidad, pero no obstante, tampoco tienen por qué provocar dolor; el dolor es producido por una mala interpretación de la contracción.

\section{Resumen del ejercicio}

19 Poner atención al endurecimiento del bajo vientre: "La contracción uterina".

$2^{\circ}$ Aplicar las dos manos sobre el vientre (el útero) en este momento para apreciarlas en forma clara y precisa.

Finalidad de este entrenamiento.-Una vez que la madre se familiariza y reconoce las contracciones uterinas, ya no necesitará aplicar sus manos sobre el vientre y en el momento del parto no habrá ningún problema; ella 
sabrá por sí misma, cuándo el parto se inicia; basta con estudiar atentamente el ritmo con que ellas aparecen y así podrá constatar cómo aí principio se suceden con diez minutos de intervalo, luego con ocho minutos, seis, cuatro, dos y por último, al finalizar el parto, cada minuto.

Téngase presente que estos datos no son matemáticos y que varían mucho en cada persona; es por este motivo por lo que la madre no debe dejar para diagnosticar el momento en que se inicia el trabajo.

\section{TERCER EJERCICIO}

A) Respiración uniforme.

B) Respiración anhelante.

A) Respiración uniforme: se trata de hacer una adaptación respiratoria para prepararse a controlar las contracciones del útero en el momento del parto.

En la respiración uniforme, como bien puede observarse por su nombre, se verifican movimientos respiratorios (inspiración y espiración) en forma rítmica y de igual intensidad tratando de aumentar la velocidad, o frecuencia mucho más allá de lo normal.

Comúnmente la mujer hace 18 o 20 movimientos respiratorios durante un minuto en reposo.

Durante la respiración uniforme se aumentará la rapidez de los movimientos hasta llegar a un ritmo de 80 por minuto, aproximadamente.

La respiración uniforme debe practicarse por la boca y no por la nariz; el motivo ce este cambio se debel solamente al hecho de que el sonido del aire que penetra y luego sale por la boca, permite controlar mejor la ejecución del ejercicio.

\section{Resumen del ejercicio}

Respiración uniforme: inspiración y espiración de la misma intensidad y velocidad durante un minuto que dura la contracción uterina.

\section{CUARTO EJERCICIO}

B) La respiración anhelante: también se la llama respiración jadeante, y es exactamente igual a la que hace el perro cuando está fatigado.

Es una respiración de gran velocidad de movimiento y por consiguiente muy superficial.

Para practicar estas dos respiraciones durante el embarazo será necesario también hacerlo en forma progresiva; al principio durante unos 20 segundos solamente 3 veces al día; en los días que siguen se aumentará su duración de a cinco segundos cada día, hasta lograr verificarlas, tanto la respiración uniforme como la anhelante, durante un minuto sin interrupción.

¿Cuáles son los fines de este entrenamiento?

1. Mayor aporte del oxígeno de la respiración que será utilizado por el músculo uterino durante el trabajo qua representa la contracción.

$2^{\circ}$ También, parte de este oxígeno será utilizado por el cerebro que en este momento se encuentra en actividad controlando y çirigiendo dicha contracción. 
$3^{\circ}$ Lo más importante es el hecho de que al respirar en forma uniforme o acelerada, y en forma anhelante o con gran velocidad, el diafragma, músculo respiratorio, verifica sus movimientos de decenso y ascenso en forma superficial y por lo tanto no alcanza a golpear el fondo del útero.

Durante la contracción uterina los receptores nerviosos que contienen las fibras musculares, se encuentran exitadas con intensidad, pero es una intensidad que no alcanza a producir exceso de excitación nerviosa cerebral; en cambio si a la irritación producida por las contracciones de las fibras musculares se agregan la excitación producida por el golpe que el diafragma produce durante las respiraciones profundas, este golpe podría, por aumento de la excitación nerviosa, desencadenar un reflejo desfavorable que puede traducirse en dolor.

Como puede comprenderse fácilmente, es en esta forma como la madre tiene en el entrenamiento y la práctica de las dos respiraciones, un arma pođerosísima para orientar, dirigir, controlar y defenderse del dolor sobre todo en aquellos casos en los cuales a pesar de los conocimientos adquiridos, pudieran presentarse algunas sensaciones dolorosas y que ella puede hacer desaparecer mediante la ejecución de estas respiraciones acelerándola o disminuyéndola, según el casoo.

\section{Resumen del ejercicio}

19. Respiración anhelante: al principio como la uniforme y poco a poco se va acelerando, como el perro cansado; al final nuevamente como la uniforme, también dura un minuto.

Durante el parto se verifica esta respiración el tiempo que dure la contracción, 40 segundos y hasta un minuto a veces.

En el intervalo entre una contracción y la que sigue se puede respirar a voluntad, como se hace normalmente; es muy conveniente respirar oxígeno puro, que se utilizará favorablemente por el músculo uterino y por el cerebro.

A) Inspiración profunda. Espiración profunda.

B) Respiración más y más superficial y rápida.

C) Respiración anhelante como la del perro cansado.

B) La respiración vuelve poco a poco a la normal.

C) Inspiración y espiración profundas.

\section{QUINTO EJERCICIO}

Período expulsivo.-También es indispensable que la madre llegue al momento del parto con un entrenamiento que le permitirá hacer del período final, el período expulsivo, a partir de la dilatación completa, un acto dirigido y consciente. Este es el momento durante el cual la madre tendrá que valerse de todas las fuerzas psíquicas y físicas adquiridas durante su preparación.

A pesar del esfuerzo exigida a la madre durante este último período, resulta curioso, por no decir increíble o sorprendente, ver cómo las madres bien preparadas logran ejecutar este período con gran serenidad y sin ningún dolor.

En este momento todos los músculos del organismo y muy especialmente el útero, el diafragma y los músculos abdominales se unen para verificar 
la fuerza que hará progresar al niño a través del canal vaginal hasta sacarlo al exterior en forma lenta y progresiva, controlada port el cerebro'de la madre.

\section{Ejercicio:}

1 i Atención a la contracción uterina.

$2^{\text {}}$ La contracción llega:

a) Se hace una inspiración muy profunda;

b) Se detiene la respiración;

c) Se levantan los hombros y la cabeza hasta llegar la barbilla sobre el pecho como para remar;

d) Se fijan o apoyan los pies en soportes;

e) Sin percier instante, se dedica la madre a hacer fuerza hacia abajo continuamente mientras dura la contracción.

\section{OBSERVACIONES}

Como la contracción uterina dura un minuto y a pesar del entrenamiento, soplando la vela, sería prácticamente imposible permanecer sin respirar, mejor dicho con la respiración contenida, durante todo el minuto, entonces se hace necesario que la madre aprovecha al máximo la contracción para pujar, soltando la respiración solamente un instante mientras vuelve a coger de nuevo otra gran cantidad de aire para seguir pujando más y más; mientras dure la contracción; una vez terminada ésta, descanso, relajación, respiración de oxígeno y alerta a la próxima contracción y así sucesivamente.

\section{LA RELAJACION MUSCULAR}

La educación neuro-muscular, conduce a la relajación muscular, y es su objeto.

Cuando un músculo trabaja, se vuelve sensible porque hay una conexión sico-física, conexión del cerebro al músculo por intermedio de los nervios respectivos.

Los nervios que parten del cerebra y se dirigen a los músculos, son los nervios motores; que llevan a dichos músculos las órdenes originadas a nivel del cerebro; órdenes de contracción, movimiento, relajación, etc.

Los nervios que parten o nacen en los músculos y se dirigen al cerebro, son los nervios sensitivos, encargados de llevar a dicho órgano (el cerebro) la impresión de que la función ha siảo verificada. El cerebro siente, se da cuenta de que la orden ha sido ejecutada, que el músculo se encuentra en contracción, en movimiento, en relajación; por eso decimos que cuanđo un músculo trabaja, se vuelve sensible.

Del cerebro sale una orden de contracción que es transmitida al msúculo por los nervios motores, el músculo reacciona, obedece la orden y se contrae; en este momento hay una excitación de los corpúsculos sensitivos que se encuentran en el interior de las fibras musculares; esta excitación se transmite de unos a otros y finalmente se reúne en un solo nervio: el nervio sensitivo, que lleva la excitación al centro cerebral; así el cerebro sabe, se da cuenta de que la orden que él dio, fue ejecutada, toma conciencia de la contracción muscular. 


\section{El cerebro es el centro principal do la contracción y relajación muscular.}

\section{Ejemplo:}

Primera orden cerebral.-Hágase una flexión, dóblese el braso sobre el antebrazo; se sentirá que el músculo del brazo se ha puesto rígido, tenso; se halla en contracción muscular.

Este fenómeno se verificó gracias a la orden que salió del cerebro y que fue transmitida por el nervia motor al músculo del brazo (actividad cerebral positiva).

Segunda orden cerebral.-Déjese caer su antebrazo hasta que éste cuelgue completamente se sentirá que el músculo del brazo, se afloja, se pone blando, ya no trabaja: es la relajación muscular.

También como en el fenómeno de la contracción muscular, aquí en la relajación muscular, el fenómeno se verificó gracias a la orden que salió del cerebro y fue transmitida por los nervios al msúculo del brazo (actividad cerebral negativa).

Es decir, que en ambos fenómenos hay actividad cerebral, en la contracción el músculo se vuelve ảuro y tenso gracias a una orden positiva, a una orden de acción, de trabajo: "Hágase la contracción"; esto es actividad cerebral positiva: contracción.

En el segunđo caso, el cerebro ordena también: "Hágase la relajación", suelte su brazo, y deberá sentir su músculo en relajación, blando, inactivo, es esto lo que llamamos actividad cerebral negativa o pasiva relajación. Es decir, que se haga movimiento o no, que se produzca contracción o relajación muscular, siempre habrá acción cerebral, actividad cerebrat.

En el sueño, y también cuando nos tiramos a la cama, o nos sentamos en la silla a descansar, se hace la relajación muscular, pero esta relajación del sueño o del descanso, es inadecuada, es simplemente inactividad muscular, no relajación activa, consciente. El sueño y el descanso disminuyen o bajan el límite de sensibilidad de los centros cerebrales y aumentan el dolor. Todos sabemos cómo se exageran los padecimientos físicos (dolores) y morales en las noches cuando nos sentamos a pensar en ellos .

La relajación muscular activa.-Es por el contrario un acto meditado, estudiado y dirigido por nuestro cerebro.

Durante el parto, sí se conocen los músculos que trabajan (útero y diafragma), y cuáles son los músculos que no deben trabajar (los demás músculos que revisten todo el esqueleto humano), no se tendrán dificultades porque así se podrá economizar oxígeno de la respiración que sirve como origen de energía uterina y cerebral.

¿Cuáles son los músculos que trabajan durante el parto? El diafragma, ei útero y los músculos abdominales durante el período final, período expulsivo.

¿Cuáles son los que no trabajan? El resto de los músculos, los músculos perineales.

Esto tiene gran importancia en el momento del parto, porque con tal conocimiento deberá tomarse una actitud activa en presencia de las contracciones, actitud directa y no pasiva o temerosa. 


\section{La relajación muscular es doblemente útil}

$1^{\text {o }}$ Porque permite una apreciable economía del oxígeno, el cual se utiliza íntegramente por los músculos que trabajan.

$2^{\circ}$ Porque ante todo contribuye a mantener el equilibrio nervioso durante el parto, ya que es el fruto de una educación, es decir, un conjunto de reflejos condicionados (por la práctica y la atención), que son capaces de oponerse a un reflejo absoluto de defensa (agitación, rigidez, bloqueo de la respiración, etc.).

Anteriormente las mujeres no decían "contracción": sino "dolor". Decían siempre: ya tengo los dolores y realmente así era, pues cada contracción uterina las crispaba, había un reflejo de defensa, puesto que la contracción era dolorosa. Sin embargo, debe ser esta contracción realmente dolorosa? O será más bien una mala interpretación del cerebro...? ¿Por qué...? Porque este tiene una tensión definiảa (voltaje) en estado normal; por ejemplo: + 4, mientras que en el sistema nervioso reurovegetativo y los órganos internos: sería de +2 . Pero si la calidad del cerebro está modificada por una emoción, su tensión baja a -2 ; mientras que la tensión de los órganos internos asciende a +4 ; hay ruptura del equilibrio nervioso. Entonces el parto se convierte en un fenómeno emocional, anormal, doloroso.

Aclaramos lo anterior con el ejemplo del telegrama anunciando la muerte de un amigo; y se habrá notado la diferencia de sensaciones que se experimentan al recibir una noticia desagradable según que uno se encuentre preparado para ella o que le llegue un cía cualquiera y de sorpresa; en el primer caso estamos preparados por las noticias previas; una larga enfermedad, el diganóstico desfavorable de los médicos, etc., en realidad ya esperábamos el desenlace y ésto no nos afecta gran cosa; en el caso contrario de muerte repentina, muerte trágica, la llegada cel telegrama a destiempo, la noticia inesperada, etc., nos produce un verdadero choque emocional que rebaja 0 anula por completo la actividad cerebral, el cerebro se asusta, se fatiga, y nebaja su volta.je de $+4 a-2$, baja, pues, el límite de sensibilidad del cerebro - y entonces empezamos a sentir de una manera desagradable los órganos internos, palpitaciones, angustia, vómitos. A pesar de que el funcionamiento es el mismo, no están enfermos y sin embargo se sienten en formo: desagradable.

Lo mismo se puede aplicar al parto, con la llegada esperada o inesperada de las icontracciones uterinas.

¿Si se esperan y conocen?... Habrá serenidad, habrá dirección, actividad cerebral, el voltaje será de +4 .

¿Si no se esperan o desconocen?... Angustia, pavor, bloqueo de la respiración, ảolor, el voltaje del cerebro cae a -2 .

Otras de las consecuencias del schok emocional, de la angustia, será el trastorno circulatorio; se conocen muy bien las palpitaciones y las sensación de angustia respiratoria producidas por los estados de temor, susto, preocupaciones, miedo; pues es exactamente lo mismo que sucede durante el parto: el cerebro angustiado es incapaz de dirigir al corazón y al aparato circulatorio; pudiendo adivinar las consecuencias sobre el útero. Este no recibe la suficiente sangre cargada de oxígeno y, por el contrario, la mala circulación 
de las fibras musculares, hace que éstas se sobrecarguen de las sustancias nocivas producidas durante las combustiones (el anhíärido carbónico).

El oxígeno va al útero por medio de la sangre: si la circulación general y uterina son norma.les, habrá buena oxigenación; en cambio si se presentan trastornos vasculares (ruptura del equilibrio nervioso), entonces se presentará la isquemia, es decir, que el útero será privado de la irrigación sanguínea. Habrá acumulación de sustancias nocivas de desecho por mala combustión, habrá intoxicación del útero; estas sustancias irritan o excitan las terminaciones nerviosas, las cuales enviarán al cerebro la orden de alarma por medio del sistema neurovegetativo; habrá contractura permanente (tetanización), calambres, por lo consiguiente habrá dolor.

Así se demuestra que únicamente es en estas condiciones cuando se presenta el dolor, cuando la contracción se ha vuelto señal del dolor.

En conclusión, la ruptura del equilibrio nervioso produce alteraciones o desequilibrios vasculares y respiratorios. El oxígeno del aire que entra con la respiración, no puede utilizarse en su debida forma, ya que no lo puede llevar correctamente a los órganos internos y a su vez estos órganos internos debido a su mala circulación, no pueden desprenderse de las substancias de desecho producidas durante las combustiones, por lo tanto se intoxican con el anhídrido carbónico que se acumula en el interior de las fibras musculares del útero, impidiendo o đificultando sus contracciones; a su vez el exceso de anhídrido carbónico allí acumulado sale poco a poco hacia la circulación sanguínea y es llevado por las venas al interior del cerebro, donde provoca también intoxicación de sus células y nervios; haciendo así que se produzca más temor, más angustia y que el parto no pueda ser dirigido correctamente. Se constituye así el llamado círculo vicioso: cerebro en desequilibrio nervioso, igual; mala respiración, mala oxigenación de la sangre y de las fibras del útero; igual; acumulación de anhídrido carbónico; igual: aumento de la dificultad de las contracciones; igual: recargo de anhídrido carbónico que intoxica más al órgano director (el cerebro).

\section{Explicación:}

$1^{\circ}$ Si el sistema nervioso está tranquilo, habrá buen trabajo, buenas combustiones y el oxígeno penetra en grandes cantidades.

$2^{\circ}$ Si el sistema nervioso está intranquilo, habrá poco trabajo de los músculos, esicasas combustiones y el oxígeno no puede entrar ampliamente.

El primero constituye un reflejo condicionado positivo, favorable: tranquiliclad, serenidad, equilibrio, dirección activa.

El segundo constituye un reflejo condicionado negativo, desfavorable: angustia, temor, susto, desequilibrio, imposibilidad para dirigir el parto.

Pero aún más: esto se convierte en un reflejo absoluto de defensa, reflejo involuntario, el cual excita más al sistema neurovegetativo y baja el límite de sensibilidad del cerebro, produciendo cada vez más dolor y el dolor más contracción.

El objeto de esta educación es tratar de obrar allí en el cerebro, tratar de obrar sobre este reflejo de defensa, procurar modificarlo adquiriendo un nuevo reflejo que sea favorable. 
¿Cuá es el métocoo para evitar que se forme este círculo vicioso? La preparación, por medio de los ejercicios de respiración y relajación muscular.

Tenienđo conciencia de los músculos abdominales y del diafragna; por medio de los ejercicios de contracción y relajación muscular, se dará cuenta de los otros músculos del cuerpo. Músculos tales como: los músculos del rostro, de las manos, de las caderas, los músculos de periné; todos ellos importantes puesto que cada uno tiene una zona consciente localizada en el cerebro: que hace que éste se ocupe de ellos en forma activa, y obteniéndose como consecuencia una elevación del nivel de sensibilidad.

Será necesario disciplina y buena voluntad. Al principio parecerán estos ejercicios muy difíciles, pero a poco se irán adaptando aprendiéndolos. La fuerza de nuestros poderes está en la voluntad. Tođas nuestras acciones se inician y verifican por el recto poder de la voluntad; por consiguiente es ella la fuente de todas nuestras acciones. Entonces, en adelante debe ponerse en práctica tales poderes internos, al servicio de un futuro hijo; no olvidando que el porvenir de ese niño que lleva en su vientre depende en gran parte del comportamiento durante el embarazo y el parto. Una madre tranquila y serena, dará un hijo tranquilo. Una madre intranquila, nerviosa, irritable, ofuscada, dará a lua un hijo en las mismas condiciones. Ponga pues en práctica los grandes poderes que tiene en la voluntad, poniéndose desde hoy y todos los días a practicar conscientemente los ejercicios que la llevarán a la victoria final: el parto sin dolor.

\section{EJERCICIO DE RELAJACION Y CONTRACCION MUSCULAR}

19 Relajación.-Acostada de espaldas completamente, respire suavemente (tome conciencia de la posición de todas las porciones del cuerpo sobre la cama: cabeza, nuca, hombros, espalda, cintura, caderas, piernas, etc.).

2: Contracción.-(Actitud activa) :

a) Contraer los músculos de la frente cerrando los ojos, relajar, respirar;

b) Contraer los músculos de la cara, cerrando las mandíbulas, relajar, respirar;

c) Contraer los hombros, relajar, respirar;

d) Contraer las caderas, relajar, respirar;

e) Contraer los brazos, cerrando los puños, soltarlos sobre la cama, relajar, respirar;

f) Contraer los pies levantándolos un poco, soltarlos, relajar, respirar;

g) Levantar un poco la cabeza y los pies al mismo tiempo (mirándolos), soltar, relajar, respirar;

h) Cerrar los párpados y quedarse en la misma posición durante $10 \mathrm{mi}$ nutos mínimo, concentrando su atención en su cuerpo, dirigiendo con su mente primero la sensación de blandura, flojedad, diciendo mentalmente: "Mi cuerpo se pone blando". Cuando ya se sienta esta sensación de blandura, pasar a la segunda orden mental que es: "Mi cuerpo entero está cada momento más pesado" y en realidad si se concentra mentalmente, y con toda la fuerza de su voluntad sostiene este pensamiento, a los pocos días empezará a notar que realmente su cuerpo se pone pesado; esto se debe a que la relajación muscular es muy buena, los músculos inmóviles no sostienen por parte alguna el esqueleto; dando la sensación del cuerpo pesado. 
Este ejercicio permite que el cerebro utilice casi en su totalidad el oxígeno circulante, a eso se debe que al terminar la relajación, se observe, que el cerebro se despeja, se acaba la fatiga, muchos dolores desaparecen: dolores lumbares, calambres en las piernas, dolores de cabeza, etc. También a medida que lo practica con entusiasmo, verá cómo su cerebro se transforma: cada día se sentirá más serenidad, tranquilidad, menos nerviosismo, y se verá, no sin sorpresa, cómo van desapareciendo uno a uno trastornos tales como máuseas, vómitos, agrieras, calambres o dolor de cabeza.

Durante el ejercicio de relajación se lanzará de cuándo en cuándo una idea de paz, tratando de repetir mentalmente la siguiente frase: "Estoy muy tranquila".

Esta idea de paz sembrada en la mente, obrará cada día más fuertemente en el cerebro, obrará en forma invasora en las células cerebrales cađa día en forma más segura y potente. Esta idea de paz, de tranquilidad, invade cada día mayor número de células del cerebro, de manera que al cabo de un tiempo, ésta se sentirá verdaderamente transformada, ya no reaccionará bruscamente, no se irritará, no se ofenderá tan fácilmente por motivos de poca importancia; el cerebro se ha vuelto extraordinariamente tranquilo, lo cual tendrá como consecuencia grandes repercuciones favorables sobre el futuro de su hogar, sobre la salua del hijo, las relaciones con su marido, en fin, el hogar será más feliz y más armonioso.

\section{Resumen del ejercicio}

$1^{\text {o }}$ Acostada de espaldas en una cama firme, palma de las manos hacia abajo.

3. Pensar: "Estoy muy tranquila" durante un minuto.

4. Pensar: "Mi cuerpo se pone blando" durante un minuto.

50 Pensar: "Mi cuerpo se pone muy pesado" durante 3 minutos.

60 Pensar: "Estoy muy tranquila" durante 3 minutos o más, si desea, sin perder la idea de peso corporal.

Medellín. - Colombia. 